\section{Wavelets and Operators}

Y. MEYER

Translated by David Salinger

The definitive mathematical treatment of this important area, written by one of the founders in this field.

f.27.95 net HB $0521420008 \quad 240$ pp. 1993

Cambridge Studies in Advanced Mathematics 37

\section{Thermodynamics of Chaotic Systems}

An Introduction

CHRISTIAN BECK and FRIEDRICH SCHLOEGL

It deals with thermodynamic methods used in nonlinear dynamics. An easy to read introduction, this book can also be used as a textbook for special courses.

f40.00 net HB $0521433673 \quad 308$ pp. 1993

Cambridge Nonlinear Science Series 4

\section{Chaos in Dynamical Systems}

\section{EDWARD OT}

An in-depth and broad text on chaos in dynamical systems, to be used both as a graduate course text for science and engineering students, and as a reference for researchers.

f45.00 net HB $0521432154 \quad 400$ pp. 1993

f16.95 net PB 0521437997

\section{Numerical Mathematics - A Laboratory Approach}

The late S. BREUER and G. ZWAS

A unique textbook that introduces computarional microcomputer laboratories as a vehicle for teaching algorithmic aspects of mathematics.

E 30.00 net HB $0521440408 \quad 320$ pp. 1993

\section{Incompressible Computational Fluid Dynamics}

Trends and Advances

Edited by MAX D. GUNZBURGER and R. A. NICOLAIDES

Contributions from leading experts in the various subfields portray the wide-ranging nature of fluid dynamics. This volume provides an entree into the current research in the field.

f35.00 net HB $052140407 \times \quad 496$ pp. 1993

\section{Probability Theory, an Analytic View}

D. W. STROOCK

A book designed to bridge the gap between probability and analysis. It will be used for graduate students requiring a classical treatment of the subject and uses a far-ranging selection of techniques.

f 30.00 net HB $0521431239 \quad 464$ pp. 1994

\section{Partial Differential Equations in Classical Mathematical Physics}

ISAAK RUBINSTEIN and LEV RUBINSTEIN

The combination of mathematical comprehensiveness and natural scientific motivation represents a step forward in the presentation of the classical theory of PDEs. f60.00 net HB $0521410584 \quad 696$ pp. 1994

\section{Iterative Solution Methods \\ OWE AXELSSON}

This book deals primarily with the numerical solution of linear systems of equations by iterative methods. It is intended to serve both as a textbook for a numerical linear algebra course and as a monograph introducing recent results in the iterative solution of linear systems. E50.00 net HB $0521445248 \quad 672$ pp. 1994

\section{Now in paperback}

\section{Hydrodynamics}

Seventh Edition

\section{HORACE LAMB}

\section{Foreword by RUSS CAFLISCH}

This reissue of the classic 1932 edition of Lamb's Hydrodynamics is an indication of this work's lasting value. Constantly in use since its publication in 1892, it has proved to be the definitive reference for all fluid dynamicists.

f19.95 net PB $0521458684 \quad 768$ pp. 1994 Cambridge Mathematical Library

\section{Group Theory and Physics}

\section{S. STERNBERG}

This textbook is a cohesive and well motivated introduction to group theory and its application to physics. Many modern topics are dealt with, making this an essential resource for physicists and applied mathematicians.

f50.00 net HB $0521248701 \quad 443$ pp. 1994

For further information write to Giulia Williams at the address below or email us on science@cup.cam.ac.uk Please call 0223-325970 to order any Cambridge book on your credit card. 
Submission of manuscripts Papers may be submitted to any member of the editorial board. Three copies should be sent; originals of figures should not be included until the paper has been accepted. Upon acceptance of a paper, the author will be asked to transfer copyright to the publisher. Papers may be submitted electronically by sending a LaTeX file to EJAM@VAX.OX.AC.UK; this file should include the figures (line figures only). Electronic communications can also be used for minor corrections and for messages to the editors.

Layout of mamuscripts Papers should be typewritten in double spacing throughout, on one side of the paper. Please avoid footnotes if possible. Papers must begin with an abstract of not more than 300 words, and they should end with a brief concluding section. The SI system of units must be used throughout. There is no formal restriction on length, but the constraint of fitting an integral number of papers into 96 pages means that short papers (20 typed pages or fewer) are likely to appear sooner than the long ones.

Illustrations Figures should be drawn in indian ink on good quality white paper or produced by computer to comparable quality. Wherever possible they will be reproduced with the author's lettering. A list of captions for figures should be attached separately.

Where appropriate, articles may be illustrated by photographs: high-quality glossy black and white prints are necessary.

References References should be listed in alphabetical order at the end of the main text. Please include the article title in the reference, which should be in the order: author's surname, initials; year in parentheses; article title; journal name, abbreviated in accordance with the World List of Scientific Periodicals (4th Edn); volume number (underlined); inclusive page numbers.

Citations in the text Any unambiguous system is acceptable. Three recommended ways of citing a 1992 paper by A. European are: European (1992); European [Eu]; European [7]. In the second case, the reference at the end of the text should be preceded by [Eu], and in the third by [7]. Please note that in the third system, alterations may lead to wholesale renumbering.

EDITORIAL POLICY

The European Journal of Applied Mathematics aims to publish papers in all areas of applied mathematics, with especial emphasis on the following.

(i) The exposition of new mathematical ideas relevant to the modelling and analysis of modern technological processes.

(ii) The development of interesting mathematical methods with broad areas of applicability.

There is no restriction in the areas of applicability or the style of mathematics as long as the content is presented so as to be as accessible as possible to the entire compunity of mathematicians and mathematical scientists. This applies in particular to the introductory section of the paper. Standard mathematical techniques will only be published if they are associated with novel applications or lead to substantial advances in established problem areas.

COPYING

This journal is registered with the Copyright Clearance Center, 222 Rosewood Drive, Danvers, MA 01923. Organisations in the USA who are also registered with the C.C.C. may therefore copy material (beyond the limits permitted by sections 107 and 108 of US copyright law) subject to payment to C.C.C. of the per-copy fee of $\$ 5.00$. This consent does not extend to multiple copying for promotional or commercial purposes. Code 0956$7925 / 94 \$ 5.00+.00$

Organisations authorised by the Copyright Licensing Agency may also copy material subject to the usual conditions.

ISI Tear Sheet Service, 3501 Market Street, Philadelphia, Pennsylvania 19104, USA, is authorised to supply single copies of separate articles for private use only.

For all other use, permission should be sought from the Cambridge or the American Branch of Cambridge University Press. $\quad$. 
European Journal of

Applied Mathematics

VOLUME $5 \cdot$ PART $3 \cdot$ SEPTEMBER 1994

\section{CONTENTS}

Travelling wave solutions of a reaction-infiltration problem and a related free boundary problem

J. CHADAM, X. CHEN, E. COMPARINI and R. RICCI

Finite amplitude convection between stress-free boundaries; Ginzburg-Landau equations and modulation theory

A. J. BERNOFF

Subsonic flow around the leading edge of a thin aerofoil with a parabolic nose

Z. RUSAK

Effective constitutive algorithms in elastoplasticity and elastoviscoplasticity

S. NEMAT-NASSER and L. NI

A simple model of the melt fracture instability

J. M. GREENBERG and Y. DEMAY

Asymptotic results for nonlinear outdiffusion

J. R. KING

Self-similar solutions of the second kind for the modified porous medium equation

J. HULSHOFF and J. L. VAZQUEZ

Nonstationary filtration in partially saturated porous media

X. CHEN, A. FRIEDMAN and T. KIMURA

Printed in Great Britain by the University Press, Cambridge

\section{CAMBRIDGE} UNIVERSITY PRESS 